\title{
Measuring Women's Autonomy in Chad Using the Relative Autonomy Index
}

\author{
Ana Vaz*, Pierre Pratley** and Sabina Alkire***
}

October, 2015

This is an Author Accepted Manuscript (AAM) of a paper published in Feminist Economics 22(1) (2016) pp. 264-294 (DOI: 10.1080/13545701.2015.1108991).

\begin{abstract}
Increasing women's voice and agency is widely recognized as a key strategy to reduce gender inequalities and improve health outcomes. Although recent studies have found associations between women's autonomy and a number of health outcomes, fundamental issues regarding adequate measurement of women's autonomy remain. The Relative Autonomy Index (RAI) provides a direct measure of motivational autonomy. It expresses the extent to which a woman faces coercive or internalized social pressure to undertake domain-specific actions. This addresses a key critique of current measures of autonomy, which focus on decisionmaking or ignore women's values. This paper examines the measurement properties and added value of a number of domain-specific RAIs using new nationally representative data from The Republic of Chad. A striking finding is that women on average have less autonomous motivation in all eight domains compared to their male counterparts.
\end{abstract}

\section{Introduction}

The increase of women's agency is widely recognized as a key strategy to reduce gender inequalities and increase productivity in developing economies, especially in Africa. Indeed, increasing women's agency is at the forefront of The World Bank's main policy objectives. The World Development Report 2012: Gender Equality and Development reiterates the importance of women's empowerment as the process through which women's agency is increased, marks empowerment as a viable strategy for international development, and emphasizes the efficiency and positive welfare outcomes of interventions aimed at supporting and facilitating the increase of women's agency.

\footnotetext{
* Ana Vaz is a Research Officer with the Oxford Poverty and Human Development Initiative (OPHI).

** Pierre Pratley is a doctoral candidate at the George Washington University and Specialist in Sustainable Development and Health Policies at WHO/PAHO.

*** Sabina Alkire is Oliver T. Carr Jr. Professor in International Affairs at the George Washington University's Elliott School of International Affairs and directs the Oxford Poverty and Human Development Initiative (OPHI).
} 
The measurement of women's agency continues to pose a challenge to researchers and policymakers, as agency is exerted differently, and with different results in different dimensions. Moreover, agency is a relational concept; it is not exerted within a social vacuum. A growing body of evidence shows that in Africa, increases in a women's agency in the household may have a different, and even negative effect on a woman's personal safety or economic agency outside the house (for reviews, see Santos and Samman, 2009; Ibrahim and Alkire, 2007; Narayan, 2005; Alsop, Bertelsen and Holland, 2006; Malhotra, Schuler and Boender, 2002; and Kishor and Subaiya, 2008).

To date, most measures of women's agency are designed to capture the concept through proxy measures such as level of education, ownership of and control over assets, employment status and control over income. The use of proxy measures is problematic for two reasons: first, the proxies may not be accurate representations of empowerment, and second the proxies themselves might be driving agency as well as the hypothesized development outcomes advanced by such an increase in agency (Alkire, 2008).

More direct indicators of women's agency have been fielded, for example in the demographic and health surveys (DHS). The DHS indicators seek to measure agency with respect to household decision-making through questionnaire items capturing a woman's self-reported decision-making on her earned income, health and freedom to visit relatives and friends. DHS surveys also contain a number of questions on perception towards gender roles such as wife beating and the ability to refuse sex with one's husband.

Proxy measures have been shown to have different associations, further validating the consensus that women's agency and empowerment are context dependent (Narayan, 2005). For example, Kishor and Subaiya's detailed twenty-three-country study of the Demographic and Health Surveys of the correlates of 23 different empowerment indicators concluded that there was no single adequate indicator of empowerment: "the finding that variables such as education, employment, and media exposure, among others, have different relationships with each of the 23 different women's empowerment variables examined in this report, suggests that these empowerment indicators are not equivalent or even close substitutes for one another". They also found that policy-relevant determinants of empowerment differed across countries and regions within countries: "different facets of women"s empowerment do not all relate in the same way to one another or to various explanatory variables" (2008:201 both quotes).

Another example is the Women's Empowerment in Agriculture Index (WEAI), a multidimensional index of empowerment constructed using the Alkire-Foster methodology, drawing on decision-making questions in relevant domains as well as information on time use, community leadership, and autonomy (which will be described more below). In pilot studies in Uganda, Bangladesh and Guatemala, the WEAI did not consistently show strong associations with age group, education, wealth quintile, or household hunger. This led the authors (who include two authors of the current study) to conclude, "there is no individual or household characteristic that is strongly associated ... with empowerment in the pilot areas of all three countries simultaneously. This exposes the weakness of some traditional proxies for 
women's empowerment including educational achievements and weal" (Alkire et al., 2013: 86-88). These findings support calls throughout the literature for novel and improved measures that further help capture the multidimensional as well as relational aspects of women's agency (Samman and Santos, 2009; Alkire, 2005; Alkire and Ibrahim, 2007; Malhotra et al., 2002).

Although authentic self-direction has long been hypothesized to drive successful development and psychological well-being (Ellerman, 2005; Sen, 1985), it is currently underrepresented in the agency and empowerment literature. This is apparent in critiques of DHS household measures, which only measure whether decisions are taken by a woman alone, jointly with her partner or by someone else. What is not examined is whether a woman values making, or not making certain decisions. For example, a woman in Chad might not care about making decisions regarding large household purchases or her employment. In this case, her choice to not be involved in these areas of decision making processes may be autonomously motivated. Current measures of agency do not distinguish whether involvement in decision-making is based on autonomous motivation, or some sort of external pressure.

Agency is considered by many to be of intrinsic value. Women who are able to exert their agency towards the advancement of goals they value and have reason to value - whether these pertain to themselves and their communities or to other subjects altogether. They do so not only to reinforce their position in society; they also value the process that has led to the achieved outcome (Levine et al., 2009). In addition, successful attainment of outcomes and increase of status in society can then lead to a host of other opportunities to exert agency and effect change. Thus, the current focus on decision making itself, which does not examine the motivations for decision making, limits the reach of quantitative measures of women's agency in the African continent.

The Republic of Chad ranks among the poorest countries in the world. According to World Bank data published in 2011, 36.5 percent of the population of Chad lives under the $\$ 1.25$ poverty line, whereas 60.5 percent of the population lives under the $\$ 2$ per day poverty line. The Oxford Poverty and Human Development Initiative (OPHI), based on 2010 Multiple Indicator Cluster Survey (MICS) data, reports that 87.2 percent of the population is multidimensionally poor, which means they are deprived in at least three out of ten indicators which include health, education and living standards. Chad is ranked 184th out of a total of 187 countries according to UNDP's 2013 Human Development Index (UNDP 2014).

The status of women in Chad is of particular concern. The maternal mortality rate in Chad is the second highest in the world with an estimated 980 deaths per 100,000 live births in 2013 (WHO: 2014 and UNICEF 2014). As of 2008, less than one in four adult women and less than half of girls were literate. In the political arena, women occupy just five per cent of parliamentary seats (UNDP 2010: 149).

To date, there has been little quantitative research on women's autonomy in Chad. Studies in the region indicate that due to religious and social norms, the autonomy of women and 
women's right to self-determination is undermined in the region, resulting in adverse health outcomes (Amzat, 2015; Hindin and Muntifering, 2011; Singh, Bloom and Brodish, 2015).

This contribution examines the measurement properties and added value of a number of domain-specific autonomy indexes in the context of The Republic of Chad. It also aims to contribute to the collection of empirical data on women's agency and empowerment in Chad, a landlocked country with some of the largest gendered economic and health inequalities in the world yet with surprisingly little data on the status of women's agency and empowerment. The analysis reveals that women on average have less autonomous motivation in all eight domains than their male counterparts. While empowerment must be approached using multiple indicators and with a deep contextual understanding, it is possible that the RAI could prove to be a particularly useful tool for policy-relevant analyses.

This contribution examines women's autonomy in Chad using a direct measure of motivational autonomy proposed by Ryan and Deci (2000). The measure is based on SelfDetermination Theory (SDT) in psychology and has recently been applied to measurement of women's relative autonomy in Bangladesh (Alkire, Quisumbing, Sraboni and Vaz, 2013). The definition of this measure of autonomy is very close to the one suggested by Sen's capability approach, and does not seem to replicate any existing measures of agency or empowerment. The measure seeks to establish autonomy as defined by the individual as positionally objective, reflecting a person's own values rather than defining it in advance. For a more detailed discussion of why this measure is relevant to human development see Alkire $(2005,2008)$.

\section{Conceptual Framework}

The Relative Autonomy Index (RAI) is a measure of motivational autonomy developed by psychologists Richard Ryan, Ed Deci, Valery Chirkov and others (Chirkov, Ryan, \& Deci, 2011; Ryan and Deci, 2000, 2012), within the context of the Self-Determination Theory (SDT). The index directly measures an individual's ability to act on what he or she values. This measure is computed with reference to specific domains or activities; which allows us to account for the variation of the individual's level of autonomy across different aspects of his or her life. Alkire has argued that the motivational approach of Ryan and Deci, and the measures of relative autonomy in particular, match Sen's concept of agency, because they refer to actions that the person values and has reason to value, and recognizing that motivations are complex, distinguishes the extent to which actions are undertaken because of their value or due to social pressure or active coercion $(2005,2008)$. SDT also permits analysis of valued agency across different cultural settings.

According to the SDT, a person is autonomous when his or her behavior is experienced as willingly enacted and when he or she fully endorses the actions in which he or she is engaged and/or the values expressed by them. People are therefore most autonomous when they act in accord with their authentic interests or integrated values and desires (Deci and Ryan, 1985; Ryan and Deci, 2000; Ryan, Deci, and Grolnick, 1995). SDT contrasts autonomous behavior 
with controlled behavior, 'in which one's actions are experienced as controlled by forces that are phenomenally alien to the self, or that compels one to behave in specific ways regardless of one's values or interests' (Chirkov et al., 2003). The RAI measures the extent to which the person's motivation for his or her behavior in a specific domain is fairly autonomous as opposed to somewhat controlled.

More specifically, human behavior is driven by intrinsic and extrinsic motivations. Intrinsic motivation is associated with the enjoyment of the activity in itself. This is the perfect example of autonomous behavior. Extrinsic motivation is the performance of a behavior in an instrumental way, i.e. with the goal of attaining an outcome aside from the behavior itself. According to the SDT, extrinsic motivation can be categorized into four different types, depending on the degree to which the individual has self-endorsed the behavior. These types are external, introjected, identified and integrated. External motivation occurs when one's action is effectively coerced - by another person, or by force of circumstances. Introjected motivation is that in which the individual acts to please others or to avoid blame - regardless of whether or not he or she personally values this particular course of action. Identified motivation occurs when the person' behavior reflects conscious valuing of self-selected goals and activities. Integrated motivation occurs when the person's actions are shaped based on his or her own system of values, goals and identities. These forms of motivation are placed on a self-determination continuum. External and introjected motivations constitute relatively controlled forms of extrinsic motivation, while identified, integrated and intrinsic motivations are considered relatively autonomous. The summary of conceptual definitions of the selfdetermination continuum is presented in Figure 1.

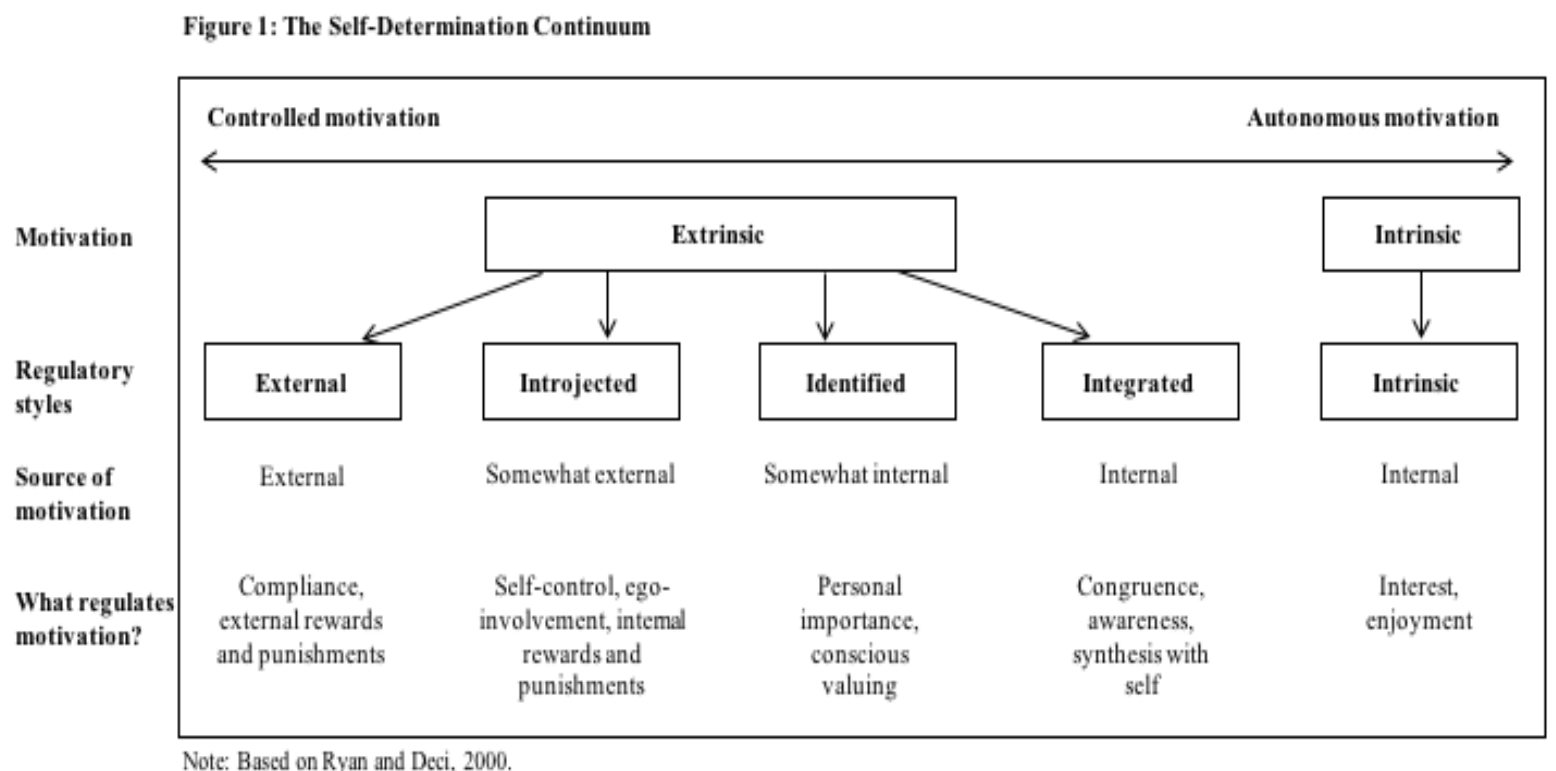

The distinction between all types of motivations is not relevant in every context (Ryan and Connell, 1989; Levesque et al., 2007). In general, the different forms of motivation are combined into one single subscale having three motivational components: external, 
introjected and autonomous motivation. The survey used in Chad included several questions aimed at capturing each of these types of motivations in each domain. The questions are based on the SDT Self-Regulation questionnaires, and were revised through several field exercises (Alkire, 2005; Alkire et al., 2013). Each question suggests a potential motivation for the respondent's actions in a specific domain and asks the individual to rate his or her level of agreement with that specific motivation, ranging from "strongly disagree" (lowest score, 1) to "strongly agree" (highest score, 4). The questions were posed regarding motivational autonomy for eight domains: (1) partaking in household activities such as cleaning the house or doing laundry; (2) employment, defined as paid work; (3) not being employed; (4) making major household purchases; (5) not making major household purchases; (6) participation in groups; (7) no participation in any group; and (8) feeding infants (women only).

Table 1: Weighting structure for Relative Autonomy Index

\begin{tabular}{|l|c|c|c|}
\hline \multicolumn{1}{|c|}{ Subscale } & Score & Weight & Weighted score \\
\hline External & 4 & $(-2)$ & $(-8)$ \\
\hline Introjected & 3 & $(-1)$ & $(-3)$ \\
\hline Autonomous & 1 & $(+3)$ & 3 \\
\hline RAI & & & $(-8)$ \\
\hline
\end{tabular}

It can be noted that some of these domains are 'positive' (employment, making major household purchases, and participating in groups) and some are 'negative' (not being employed, not making major purchases, not participating in groups). Each respondent pertained to one of these two domains, and the questionnaire sought to elucidate their motivation for that particular action. We will discuss below the finding that the RAI scores on 'positive' domains were being much larger than those on 'negative' domains for all groups (women, men, household heads, spouses, and daughters - see Tables 5.1 and 5.2).

The wording of the survey items fielded in this study are presented in Table A.1 in Annex.

The score for each motivation subscale corresponds to the mean of the items that capture that type of motivation. ${ }^{1}$ The Relative Autonomy Index is the weighted sum of the person's scores in the subscales. The subscales weights are a function of their position in the selfdetermination continuum. The standard weighting structure for a RAI incorporating three types of motivation is: -2 for external motivation, -1 for introjected motivation and +3 for autonomous motivation. The RAI, thus, varies between -9 and 9 . Positive scores are interpreted as indicating that the individual's motivation for his or her behavior in that

\footnotetext{
${ }^{1}$ In the computation of the mean we consider all items with no missing information. For instance, suppose there are four questions that capture external motivation. We are able to compute the external score motivation for all individuals that answered at least one of these four questions. If the individual only answered one question, the score will be the score of that question; if the individual answered three of these questions, the external motivation score will be the average of the score of those three questions. The main advantage of this scoring method is that allows us to keep in the sample individuals that did not answer all the autonomy questions. A potential disadvantage is that we have individuals with motivation scores computed with reference to different sets of questions.
} 
specific domain tends to be relatively autonomous; while negative scores indicate a relatively controlled motivation.

For example, let's take the example of Miriam, a woman who works in a factory and earns a salary - which is very important to her. ${ }^{2}$ Manufacturing is thought to be a 'good job' by her family who pushed very hard for her to take this job. But she doesn't enjoy the work; indeed she thinks it is dangerous and boring. She does it for the salary and prestige within her family - only. She answered "Strongly agree" to the external motivation questions (she does it to get a reward, the salary); "Agree" to the introjected motivation questions (she does it to please others); and "Strongly disagree" to the autonomous motivations questions (she does not enjoy it and it is not important to her personally). So, her RAI is computed as follows:

The RAI measures the ability of a person to act on what he or she values. The RAI can indicate where autonomous motivation prevails over motivations to please others or to avoid punishment, probes the person's own understanding of the situation and enables the respondent to easily explain different motivations that influence certain activities (Alkire, 2008).

In this study we use the terms RAI, relative autonomy and motivational autonomy interchangeably.

\section{Data}

\subsection{Survey}

This study uses data from the nationally representative Multidimensional Poverty and Vulnerability in Chad (EPMVT) household survey. EPMVT was designed and collected by the Institute of National Statistics of the Government of Chad (INSEED), the Oxford Poverty and Human Development Initiative (OPHI) at Oxford University and UNICEF-Chad. This survey was designed to provide information on standard socio-economic variables and five additional 'missing dimensions' of poverty data, namely on work quality, physical safety, empowerment, dignity and psychological wellbeing. The Household Questionnaire and the Main Questionnaire used in the EPMVT were adapted from the Demographic and Health Survey (DHS), UNICEF's Multiple Indicator Cluster Survey (MICS), and OPHI's Missing Dimensions of Poverty survey modules instruments. The questionnaires were translated into French and Arabic.

Trainings of INSEED supervisors and enumerators were conducted. The survey team was instructed on the questionnaires, in order to ensure overall understanding of the main questions, as well as how to translate the concepts into local languages. A pilot survey was conducted in the end of February 2012, data collection was conducted May through July 2012 (Zavaleta, 2015).

\footnotetext{
${ }^{2}$ Example is from page 2 of OPHI's agency module, http://www.ophi.org.uk/wp-content/uploads/May-2012.pdf?a403e4
} 
Among selected households, both the head of household and any women aged 15 years or older were interviewed, yielding a unique sample that enables us to compare the relative autonomy between women and their husbands, and women in relation to the household head. The sample includes 3,365 men and 6,232 women aged 15 years or older in 4,426 households. However, as in each domain of decision-making, autonomy information was collected for those respondents who actually make decisions in that domain, the eligible sample for each domain may be smaller (Table 2).

The EPMVT used the same sampling frame employed in the ECOSIT 3 national household survey in order to create a sub-sample of the ECOSIT 3 dataset. This enabled the questionnaire to be merged with the ECOSIT 3 variables for consumption and expenditure, which provides high quality information on the monetary situation of the household which greatly enriches the analysis.

\subsection{Variables}

In this study we also use indicators of wellbeing and information on individuals' and their household characteristics.

Table 2 : Size of the sample with RAI information by domain

\begin{tabular}{lcccc}
\hline & \multicolumn{2}{c}{ Sample of women } & \multicolumn{2}{c}{ Sample of men } \\
Domain & Size & \% of missing & Size & \% of missing \\
\hline Household Activities & 5,485 & 1.6 & 3,077 & 1.4 \\
Employment & 2,197 & 11.5 & 2,344 & 6.2 \\
No Employment & 2,970 & 18.2 & 706 & 16.6 \\
Household Purchases & 629 & 2.8 & 1,031 & 1.3 \\
No Household Purchases & 4,559 & 7.8 & 2,088 & 5.0 \\
Participation in groups & 1,717 & 5.5 & 1,394 & 3.5 \\
No participation in groups & 3,505 & 10.8 & 1,679 & 7.7 \\
Feeding infants & 1,094 & 28.3 & - & - \\
\hline \hline
\end{tabular}

Note: $\%$ of missing refers to eligible respondents for the question who did not complete it.

Our dataset includes the psychological and subjective wellbeing indicators proposed by Samman (2007). The indicators proposed by Samman can be divided into three different categories. The first indicator focuses on "the extent to which people perceive meaning in their lives" (Samman, 2007: 460). The second set of indicators attempts to measure the psychological needs identified by the self-determination theory: autonomy, competence and relatedness. The third set of indicators focuses on overall and domain-specific life satisfaction. This list is closed with a happiness indicator. Our dataset also includes the indicator of individual's sense of agency, measured with a ladder question. The wording of the survey questions are presented in Table A.2 in Annex.

For the subsample for which we are able to merge the EPMVT and the ECOSIT3, we have information on the household expenditure, as well as the national expenditure poverty line. Based on this information we constructed two variables: household poverty status (which is 1 
if the household total expenditure is below the national poverty line and zero otherwise) and household expenditure per capita quintiles.

The summary statistics of all the variables used are presented in Annex. ${ }^{3}$

\section{Validity and Reliability}

In this section we probe the validity and reliability of the data on relative autonomy. In a first stage, we examine whether the data collected is consistent with the main hypotheses of our measurement model. In a second stage, we perform a standard reliability test to assess the internal consistency of the autonomy scale as a whole.

\subsection{Conceptual Validation}

The measurement model rests in two main hypotheses:

(1) There are three dimensions in our autonomy data. Each of these dimensions reflects one of the latent characteristics that we are attempting to measure: external, introjected and autonomous motivations.

(2) There is an ordered correlation among the motivation subscales. As the subscales correspond to a continuum of autonomy, we expect that adjacent subscales correlate more strongly than subscales further apart on the continuum (Ryan and Connell, 1989). ${ }^{4}$

In the subsections below we examine into what extent each of these assumptions is verified in our autonomy data.

\subsubsection{Dimensional Structure}

For each domain of decision-making, we examine the structure of motivation data. We investigate if the data reflects the three dimensional structure, and if each dimension captures a different type of motivation: external, introjected and autonomous.

Similarly to Guio, Gordon and Marlier (2012), we use two different statistical methods to investigate the structure of the data: a factor analysis and a cluster analysis.

\section{Factor Analysis}

For each domain of decision-making, we perform an exploratory factor analysis (EFA). To facilitate the interpretation of the results, we rotate the axes. Since the motivation subscales

\footnotetext{
3 The RAIs included in this table already incorporate the modifications that resulted from the validity and reliability analysis.

${ }^{4}$ While the terminology might be interpreted to imply that identified motivation is negatively correlated with external and introjected motivations, the external and identified motivations are not necessarily negatively correlated, but are likely to have very low correlations since they are on the opposite extremes of the scale (Ryan, personal communication).
} 
are likely to be correlated, we use oblique rotation. This analysis is done separately by gender.

The EFA results are relatively similar between the sample of women and the sample of men. These results suggest that in all domains there are only two dimensions or less. According to Kaiser criterion, in some domains of decision-making we should only retain one factor, i.e. there is evidence of only one dimension. ${ }^{5}$ On average across domains the first factor accounts for approximately 90 percent of the variance in both samples of women and men. Nevertheless, if we retain two factors we find that controlled and autonomous motivation questions are discriminated in different factors, with very few exceptions. ${ }^{6}$

\section{Cluster Analysis}

For each domain and gender sample, we perform a cluster analysis to investigate if the motivation questions are grouped according to the type of motivation they are intended to measure. We compute a proximity matrix based on the squared Euclidean Distance. Then, clusters are produced using the hierarchical average linkage method. In all domains with the exception of no employment, the Calinski-Harabasz and the Duda-Hart stopping rules suggest that there is a two-cluster structure. Looking at the dendograms we find that the two broad clusters tend to discriminate controlled and autonomous motivations. Similarly to what we find in the EFA, there are very few questions that are grouped in a cluster different from the one we expected. ${ }^{7}$

Overall, the structure that emerges from this analysis corroborates the separation between controlled and autonomous motivations. The empirical evidence, however, does not distinguish between external and introjected motivations. For the purpose of distinguishing more empowered and less empowered women and men, retaining two factors may be sufficient. In addition, it may permit shortened surveys in future.

This analysis also identifies two questions that in some domains seem to be capturing a motivation different from the one that they were designed to, namely:

\footnotetext{
${ }^{5}$ According to Kaiser criterion we should retain the factors that have an eigenvalue equal or higher than 1.0. In our data, only in the domains of household activities and participation in groups there are two factors with an eigenvalue higher than 1.0. In all other domains there is only one factor with an eigenvalue higher than 1.0. This is true for both samples of women and men.

${ }^{6}$ The question that asks individuals if they do what they do because they get a reward or a benefit, designed to capture external motivations, is grouped with autonomous motivation questions in several domains. This occurs in both samples of women and men in the domains no employment, household purchases and group membership; it only occurs in the sample of women in the domains employment and no household purchases. On the other hand, the item 'I don't think it is valuable to participate', aimed at capturing identified motivations, is grouped in the factor of the external motivations in the domain of no group membership, in the sample of men.

7 The item 'get a reward or a benefit' is grouped with autonomous motivation questions in the domains employment, household purchases and group membership. The item 'I don't think it is valuable to participate' is also grouped in the cluster of the external motivations in the domain of no group membership. In the domain no employment the item 'I do not like to work', which aims at capturing intrinsic motivation, is included in controlled motivation cluster.
} 
- 'I will get a benefit or a reward', in the domains related to employment and household purchases, and in group participation; and

- 'I don't think is valuable to participate', in the domain no participation in groups.

Based on this evidence, these items will not be considered in the computation of the motivation subscales in these domains.

\subsubsection{Correlations within Areas of Decision-Making}

Since the motivation subscales correspond to a continuum of autonomy, we expect adjoining subscales to be more correlated than subscales in opposite extremes. To investigate if our data adheres to this hypothesis, we compute Spearman and Pearson correlation matrices for each domain, considering the samples of men and women separately. These matrices are presented in Table $3 .^{8}$

The patterns of correlation for men and women are very similar. The ordered correlation pattern hypothesis is verified in most domains and in both samples. The correlation between external and autonomous motivations is the lowest in the matrix in most domains; the only exceptions are no household purchases and no group membership. In the domains household purchases, group membership and employment (when considering the sample of women) the Spearman correlation between external and autonomous motivations are negative (which is expected). In all domains the highest correlation is between external and introjected motivations (which is also expected).

\subsection{Reliability}

In this section we examine the internal consistency of the scale as a whole using Cronbach's Alpha, which reflects the extent to which a set of items measures a latent construct. We computed the Cronbach's Alpha for each autonomy subscale in each domain, separately for women and men (results available upon request). We found that the internal consistency of most motivation subscales is acceptable or good (Alpha between 0.6 and 0.9). In the domain household purchases the internal consistency of all the three motivation subscales is poor or even unacceptable in both women and men samples (Alpha below 0.6 or 0.5 ). In the sample of men, all the three subscales have poor internal consistency in the domain of employment.

\footnotetext{
${ }^{8}$ The external and autonomous subscales scores were computed taking into consideration the results of the previous section i.e. disregarding the items that did not seem to capture the type of motivation that they were supposed to.
} 
Table 3: Matrix of correlations between motivation subseales

\begin{tabular}{|c|c|c|c|c|c|c|c|c|c|c|}
\hline \multirow[b]{3}{*}{ Houschold aetivitiex } & \multicolumn{5}{|c|}{ Sample of women } & \multicolumn{5}{|c|}{ Sample of men } \\
\hline & \multicolumn{2}{|c|}{ Spearman } & \multicolumn{2}{|c|}{ Pearson } & \multirow[t]{2}{*}{ Obs. } & \multicolumn{2}{|c|}{ Spearman } & \multicolumn{2}{|c|}{ Pearson } & \multirow[t]{2}{*}{ Obs. } \\
\hline & External & Introj. & External & Introj. & & External & Introj. & External & Introj. & \\
\hline Introjected & $0.65^{* 4 *}$ & & $0.65^{* 4 *}$ & & & $0.61^{* 4 *}$ & & $0.63^{* 4 *}$ & & \\
\hline Identified & $0.19 * 4 \times$ & $0.25^{* 4 *}$ & $0.25^{* 4 *}$ & $0.28=4 x$ & 5,485 & $0.13^{* 4 *}$ & $0.19 * 4 *$ & $0.19 * 4 \times$ & $0.24^{* 4 x}$ & 3,077 \\
\hline Employment & External & Introj. & External & Introj. & & External & Introj. & External & Introj. & \\
\hline Introjected & $0.53^{* 4 *}$ & & $0.54^{* 4 x}$ & & & $0.55^{* 4 * x}$ & & $0.56^{x 4 x}$ & & \\
\hline Identified & -0.02 & $0.14^{* 4 x}$ & 0.03 & $0.18=4 x$ & 2,197 & 0.03 & $0.15^{* 4 *}$ & $0.0 \mathrm{~g}^{\mathrm{*} * \mathrm{x}}$ & $0.19 * 4 x$ & 2,344 \\
\hline No employment & External & Introj. & External & Introj- & & External & Introj. & External & Introj. & \\
\hline Introjected & $0.66^{x+x}$ & & $0.70^{* * * x}$ & & & $0.65^{* 4 *}$ & & $0.63^{* 4 *}$ & & \\
\hline Identified & $0.40^{* 4 * x}$ & $0.48 * 4 x$ & $0.35^{* 4 *}$ & $0.42^{* * * x}$ & 2,970 & $0.46^{* 4 *}$ & $0.55^{* 4 *}$ & $0.43^{* 4 *}$ & $0.52^{* 4 *}$ & 706 \\
\hline Making purchases & External & Introj. & External & Introj- & & External & Introj. & External & Introj. & \\
\hline Introjected & $0.55^{* * *}$ & & $0.52^{* 4 *}$ & & & $0.57^{* * *}$ & & $0.57^{* 4 *}$ & & \\
\hline Identified & -0.07 & -0.05 & 0.00 & 0.02 & 629 & -0.04 & 0.01 & 0.01 & 0.04 & 1,031 \\
\hline Not making purchuses & External & Introj. & External & Introj- & & External & Introj- & External & Introj. & \\
\hline Introjected & $0.64^{* 4 *}$ & & $0.64^{* 4 *}$ & & & $0.65^{* 4 *}$ & & $0.61^{* 4 *}$ & & \\
\hline Identified & $0.44^{* 4 x}$ & $0.42^{2 * * x}$ & $0.40^{x * x}$ & $0.38 * 8 x$ & 4,559 & $0.41^{\approx * * x}$ & $0.41^{x * x}$ & $0.37 * 4 \times$ & $0.37 * 4 *$ & 2,088 \\
\hline Participation in groups & External & Introj. & External & Introj. & & External & Introj. & External & Introj. & \\
\hline Introjected & $0.57^{* 4 *}$ & & $0.59=* \approx$ & & & $0.60^{* 4 *}$ & & $0.63^{* 4 *}$ & & \\
\hline Identified & $-0.10^{* * * *}$ & 0.06 & -0.03 & $0.12^{2 * * x}$ & 1,717 & $-0.14^{* * *}$ & -0.02 & -0.06 & 0.05 & 1,394 \\
\hline No participation in groups & External & Introj. & External & Introj. & & External & Introj. & External & Introj. & \\
\hline Introjected & $0.74^{* * *}$ & & $0.75^{* 4 *}$ & & & $0.73^{* 4 *}$ & & $0.73^{* * *}$ & & \\
\hline Identified & $0.42^{* * x}$ & $0.39 * 4 \times$ & $0.37 * 4 *$ & $0.32^{* 4 *}$ & 3,5015 & $0.45^{* 4 *}$ & $0.43 * 4 *$ & $0.42^{* 4 *}$ & $0.39 * * *$ & 1,679 \\
\hline Feeding infants & External & Introj. & External & Introj. & & External & Introj. & External & Introj. & \\
\hline Introjected & $0.60^{* * * *}$ & & $0.59=4 \approx$ & & & & & & & \\
\hline Identified & 0.07 & $0.14^{* 4 x}$ & $0.12^{* 4 *}$ & $0.19=4 \times$ & 1,094 & & & & & \\
\hline
\end{tabular}


As a further reliability test we conduct the Mokken Scale Procedure (MSP). This procedure selects "unidimensional scales of polytomous items from multidimensional datasets" (Hemker, Sijtsma and Molenaar, 1995: 337). In most domains the Mokken Scale Procedure identifies two scales, one with the items referring to controlled motivations and other with the items measuring autonomous motivations. Most of these scales are of medium quality.

\subsection{Alternative Relative Autonomy Index}

Our validity analysis does not provide evidence of a distinction between external and introjected motivations. It is possible that the distinction between these two types of motivation is not relevant in this context. In these circumstances, we computed the relative autonomy index based on only two broad types of motivation: controlled and autonomous. The score of controlled motivation corresponds to the average of the items aimed at capturing external and introjected motivations. This RAI is the weighted sum of the score of the controlled motivation, with a weight of -3 , and the score of the autonomous motivation, with a weight of $3 .{ }^{9}$

Comparing the RAI based on two types of motivations with the one based on three, we find that the Spearman correlation coefficient is equal or above 0.95 for all domains (in both samples of men and women). This evidence suggests that a measure of relative autonomy based only on two broad types of motivation may capture the same information as a measure based on three types of motivations. If that is the case, we may compute individuals' relative autonomy with base on a smaller number of questions and, thus, reduce the survey costs of collecting such information.

In the remainder of this study we will use the RAI based on two types of motivations, controlled and autonomous, because this dimensional structure seems to better fits our data. ${ }^{10}$

\section{Relationship between Relative Autonomy and other Indicators}

In this section we investigate the relationship between the RAI in different domains, and between these and other indicators of well-being. We base this analysis on the Pearson correlation. The coefficients and the respective significance levels were estimated taking into consideration the survey design.

Table 4 presents the correlations between RAIs in the different domains. The table shows that autonomy in Household Activities and Employment are significantly correlated with autonomy in all domains considered, but that in all cases the correlations are below 0.40 , for

\footnotetext{
${ }^{9}$ We use the weights of -3 and 3 to define this alternative RAI in the same range (between -9 and 9 ) as the original RAI.

10 Ideally, qualitative information would be required in order to establish that the conceptual framework of respondents has only two categories, and to rule out the possibility that the distinctions are clouded by issues in translation or enumeration. Unfortunately, it was not possible to collect this kind of information within the scope of this project.
} 
women and 0.47 for men. These findings are in agreement with previous findings that most dimensions of autonomy are moderately related (Agarwala and Lynch, 2006, Balk, 1994). On the other hand, autonomy in No Employment is only significantly correlated in a few domains. The correlation is especially strong among autonomy in 'active' domains (Household Activities, Employment, Household Purchases, Participation in Groups and Feeding Infants) as was found in Balk (1994). Interestingly, autonomy in Feeding Infants is only statistically correlated with autonomy in other active domains.

We now turn to investigate the correlation between the RAI and the indicators of psychological well-being: purpose, overall autonomy, competence and relatedness. The correlation coefficients are presented in columns (1) to (4) of Table 5. Autonomy in the active domains Household Activities, Employment, Making Purchases and Participation in Groups is positively associated with higher levels of autonomy, competence and relatedness. Among women, sense of purpose is only significantly correlated with autonomy in employment. Among women, overall autonomy is only correlated with RAIs in household activities, employment, no employment and no participation in groups. The RAI for Feeding Infants is not correlated with any indicator of psychological well-being.

Now we analyze correlations between RAIs and domain-specific life satisfaction (columns (5) to (10) of Table 5). We find no significant positive relationship between relative autonomy in different domains and satisfaction with life overall. In fact, women with higher levels of relative autonomy in Household Activities and Participation in Groups, and men with higher relative autonomy in Household Activities and No Employment tend to report lower satisfaction with life overall. In the case of men, being the household head and not working may be associated with the idea of failure to provide for one's family. Maybe men who have been out of work for a longer period end up adapting to their new 'status' and report higher levels of autonomy in no employment. The evidence that higher levels of autonomy in no employment are also negatively associated with men's satisfaction with their dignity is consistent with this explanation.

The clearest pattern in this analysis is that women's relative autonomy in most domains is significantly correlated with satisfaction with free choice and control over life. In particular, women's relative autonomy in Feeding Infants is only statistically correlated with this particular indicator of satisfaction. Yet the correlations are weak, not exceeding 0.10.

There is no evidence of a positive relationship between individuals' RAIs and their happiness. In fact, for both men and women, relative autonomy in Household Activities and Participation in Groups is negatively correlated with happiness.

Finally and surprisingly, individual's relative autonomy is not significantly correlated with their self-reported agency, measured by the standard ladder question, in any domain for either gender. This indicates that autonomy scales provide information that is distinct from the commonly used questions to measure agency. This finding may appear surprising. 
Table 4: Pearson correlations between RAI in different domains

\begin{tabular}{|c|c|c|c|c|c|c|c|c|}
\hline Domains & $\begin{array}{l}\text { Houschold } \\
\text { activities }\end{array}$ & Employment & No employment & $\begin{array}{l}\text { Making } \\
\text { purchases }\end{array}$ & $\begin{array}{c}\text { Not making } \\
\text { purchases }\end{array}$ & $\begin{array}{l}\text { Participation in } \\
\text { groups }\end{array}$ & $\begin{array}{c}\text { No } \\
\text { participation in } \\
\text { groups } \\
\end{array}$ & $\begin{array}{l}\text { Feeding } \\
\text { children }\end{array}$ \\
\hline \multicolumn{9}{|c|}{ Sample of women } \\
\hline Houschold activities & 1.00 & & & & & & & \\
\hline Employment & $0.39 * \approx *$ & 1.00 & & & & & & \\
\hline No employment & $0.11^{* *}$ & . & 1.00 & & & & & \\
\hline Making purchases & $0.35^{* * *}$ & $0.34^{* * *}$ & 0.02 & 1.00 & & & & \\
\hline Not making purchases & $0.15^{* * *}$ & $0.19^{\approx * \approx}$ & $0.20^{* \approx *}$ & . & 1.00 & & & \\
\hline Participation in groups & $0.36^{* * *}$ & $0.32^{* * *}$ & 0.06 & $0.22^{* *}$ & $0.09^{*}$ & 1.00 & & \\
\hline No participation in groups & $0.23^{* * 8}$ & $0.18^{* * *}$ & $0.17^{* * *}$ & $0.26^{* * 8}$ & $0.20^{* * *}$ & . & 1.00 & \\
\hline Feeding infants & $0.31^{* * *}$ & $0.28^{* \approx *}$ & -0.10 & $0.50^{* \approx *}$ & 0.05 & $0.25^{* * *}$ & 0.09 & 1.00 \\
\hline \multicolumn{9}{|c|}{ Sample of men } \\
\hline Houschold activities & 1.00 & & & & & & & \\
\hline Employment & $0.40^{* \approx *}$ & 1.00 & & & & & & \\
\hline No employment & $0.11^{*}$ & . & 1.00 & & & & & \\
\hline Making purchases & $0.33^{* \approx *}$ & $0.31^{* * *}$ & 0.12 & 1.00 & & & & \\
\hline Not making purchases & $0.15^{* *}$ & $0.14^{* *}$ & 0.12 & . & 1.00 & & & \\
\hline Participation in groups & $0.46^{* * *}$ & $0.39^{* * *}$ & 0.06 & $0.36^{* * *}$ & $0.16^{* *}$ & 1.00 & & \\
\hline No participation in groups & $0.32^{* \approx *}$ & $0.21^{* \approx *}$ & $0.26^{* \approx}$ & 0.14 & $0.23^{* \approx *}$ & r & 1.00 & \\
\hline
\end{tabular}

Note: ${ }^{* 4 *} \mathrm{p}<0.01,{ }^{* *} \mathrm{p}<0.05,{ }^{*} \mathrm{p}<0.1$ 
Table 5: Pearson correlations between RAI and psychological and subjective wellbeing indicators

\begin{tabular}{|c|c|c|c|c|c|c|c|c|c|c|c|c|}
\hline \multirow{3}{*}{ RAI in domain... } & \multirow{2}{*}{$\begin{array}{l}\text { Meaning } \\
\begin{array}{l}\text { Sense of } \\
\text { purpose }\end{array}\end{array}$} & \multicolumn{3}{|c|}{ Psychological Wellbeing } & \multicolumn{6}{|c|}{ Satisfaction with one's... } & \multirow{2}{*}{$\begin{array}{l}\text { Subjective } \\
\text { happiness }\end{array}$} & \multirow{2}{*}{$\begin{array}{l}\text { Sense of } \\
\text { agency }\end{array}$} \\
\hline & & Autonomy & Competence & Relatedness & Life overall & $\begin{array}{c}\text { Free choice } \\
\text { and control } \\
\text { over life }\end{array}$ & Dignity & Income & Health & Work & & \\
\hline & (1) & (2) & (3) & (4) & (5) & (6) & (7) & (8) & (9) & $(10)$ & (11) & (12) \\
\hline & \multicolumn{12}{|c|}{ Sample of Women } \\
\hline Houschold activities & 0.04 & $0.12^{28 *}$ & $0.12^{* 8 * 8}$ & $0.11^{* * *}$ & $-0.09 * *$ & $0.07^{* 8}$ & 0.02 & $-0.13^{* * *}$ & $-0.05^{*}$ & $-0.09 * * *$ & $-0.06^{*}$ & 0.01 \\
\hline Employment & $0.11^{* 8 *}$ & $0.14^{* 8 * 8}$ & $0.10^{* 8}$ & $0.16^{28 *}$ & -0.03 & $0.09^{* 8}$ & $0.10^{* 8}$ & $-0.10^{* *}$ & 0.02 & -0.04 & 0.02 & 0.06 \\
\hline No employment & 0.03 & $0.07^{* *}$ & 0.07 & -0.07 & 0.04 & $0.05^{*}$ & 0.00 & $0.07^{*}$ & 0.03 & 0.05 & 0.04 & 0.04 \\
\hline Make purchases & 0.11 & 0.11 & $0.20^{* 8}$ & $0.25^{* 8 *}$ & -0.09 & 0.04 & -0.03 & -0.14 & -0.10 & -0.07 & -0.02 & 0.04 \\
\hline Not making purchases & 0.01 & 0.04 & $0.05^{*}$ & 0.03 & 0.05 & $0.08^{* * *}$ & $0.07^{* * *}$ & $0.06^{*}$ & 0.03 & 0.04 & 0.02 & 0.04 \\
\hline Participation in groups & 0.06 & 0.04 & $0.13^{* * *}$ & $0.11^{* *}$ & $-0.14^{* *}$ & -0.03 & -0.04 & $-0.20^{* * *}$ & -0.06 & $-0.12^{* * *}$ & $-0.10^{*}$ & -0.04 \\
\hline No participation in groups & 0.04 & $0.10^{* *}$ & $0.12^{* * 8}$ & $0.08^{*}$ & 0.00 & 0.08 & $0.09^{*}$ & $-0.07^{*}$ & -0.02 & $-0.08^{* *}$ & -0.05 & 0.00 \\
\hline \multirow[t]{2}{*}{ Feeding infants } & -0.03 & 0.02 & 0.03 & 0.07 & 0.02 & $0.10^{* 8}$ & 0.04 & -0.03 & 0.05 & -0.01 & 0.01 & 0.07 \\
\hline & \multicolumn{12}{|c|}{ Sample of Men } \\
\hline Houschold activities & 0.03 & $0.11^{* 8 *}$ & $0.15^{* 8 *}$ & $0.13^{* 8 *}$ & $-0.08^{*}$ & $0.07^{*}$ & 0.04 & $-0.16^{* * *}$ & -0.03 & -0.06 & $-0.10^{* 4}$ & 0.00 \\
\hline Employment & $0.09^{* *}$ & $0.10^{* * 8}$ & $0.13^{\approx * 8}$ & $0.09^{*}$ & -0.02 & 0.02 & 0.04 & $-0.07^{*}$ & 0.00 & $-0.07^{* *}$ & -0.03 & 0.02 \\
\hline No employment & -0.03 & -0.03 & -0.07 & -0.03 & $-0.09 *$ & -0.01 & $-0.12^{* *}$ & 0.01 & 0.00 & 0.03 & -0.06 & -0.03 \\
\hline Make purchases & $0.14^{* 8 *}$ & $0.14^{* \approx}$ & $0.15^{* * *}$ & $0.11^{* *}$ & 0.03 & -0.01 & 0.00 & -0.05 & 0.00 & 0.00 & -0.04 & 0.02 \\
\hline Not making purchases & 0.02 & 0.02 & 0.03 & $-0.12^{* *}$ & 0.02 & 0.04 & 0.05 & $0.10^{* * 8}$ & $0.09^{* \approx *}$ & 0.04 & $0.07^{*}$ & 0.02 \\
\hline Participation in groups & 0.03 & $0.16^{* * *}$ & $0.22^{* 8 *}$ & $0.12^{* *}$ & -0.04 & 0.04 & $0.08^{*}$ & $-0.09^{* *}$ & $-0.10^{* *}$ & $-0.09^{* *}$ & $-0.099^{* *}$ & 0.01 \\
\hline No participation in groups & -0.05 & 0.02 & 0.06 & 0.03 & 0.01 & 0.05 & -0.04 & $-0.13^{* * *}$ & -0.01 & $-0.08^{*}$ & -0.02 & -0.02 \\
\hline
\end{tabular}

Note: ${ }^{* 4 *} \mathrm{p}<0.01,{ }^{* *} \mathrm{p}<0.05,{ }^{*} \mathrm{p}<0.1$ 
However the standard ladder question may also reflect personality traits such as optimism and extroversion, or cultural traits such as non-linear scales or capped aspirations (Narayan 2005). The 'scale' of the ladder may be differently interpreted, leading to issues in data comparability across persons as well as over time.

In summary, relative autonomy does not duplicate information presented by indicators of psychological wellbeing or of subjective wellbeing. There are no significant correlations between the 'ladder' question, and the most significant correlations are with psychological well-being indicators and satisfaction with 'free choice and control' (for women only). But the magnitudes of all correlations discussed here are weak. The highest correlation we find is of 0.25 ; most are weaker - for example those with 'free choice' are 0.10 or below. These findings suggest that neither indicators of subjective nor psychological well-being are sufficiently precise proxies for motivational autonomy. And they underscore the need for direct measures of autonomy.

\section{Correlates of Relative Autonomy}

This section investigates the association between domain-specific relative autonomy and individual and household characteristics. We start by looking at the correlation coefficients, and then we move to a multivariate regression analysis. The main purpose of this section is to explore how relative autonomy varies across relevant subgroups.

\subsection{Comparing Autonomy by Gender}

First of all, we look at the relationship between autonomy and gender. Table 6.1 presents the correlation coefficient between each RAI and gender, the mean RAI in the sample of women and men, and the $p$-test for the difference of the means between genders. The variable gender is 1 if individual is a man and 2 if is a woman. This table shows that on average women are less autonomously motivated than men across all domains, except making Household Purchases. The differences in relative autonomy are largest in the domains of Household Activities and Employment.

Table 6.1 Correlation and mean comparisons of RAI's across gender

\begin{tabular}{|c|c|c|c|c|c|c|}
\hline \multirow[t]{2}{*}{ RAI in... } & \multirow{2}{*}{$\begin{array}{c}\text { Pearson } \\
\text { Correlation }\end{array}$} & \multicolumn{2}{|c|}{ Male sample } & \multicolumn{2}{|c|}{ Female sample } & \multirow{2}{*}{$\begin{array}{c}\begin{array}{c}\text { Means } \\
\text { comparison }\end{array} \\
\text { Difference }\end{array}$} \\
\hline & & Mean & Obs & Mean & Obs & \\
\hline & (1) & $(2)$ & $(2)$ & (5) & (7) & $(8)$ \\
\hline Houschold Activities & $-0.13^{* * *}$ & 2.91 & 3,077 & 2.18 & 5,485 & $-0.71^{* * 4}$ \\
\hline Employment & $-0.15^{* * *}$ & 3.72 & 2,344 & 2.86 & 2,197 & $-0.73^{* * *}$ \\
\hline No Employment & $-0.10^{* * *}$ & 0.77 & 706 & 0.32 & 2,970 & $-0.41^{* * *}$ \\
\hline Making Household Purchases & 0.00 & 4.03 & 1,031 & 4.05 & 629 & -0.05 \\
\hline Not making Houschold Purchases & $-0.13^{* * *}$ & 0.46 & 2,088 & 0.25 & 4,559 & $-0.56 * * *$ \\
\hline Participation in Groups & $-0.05^{* *}$ & 4.06 & 1,394 & 3.77 & 1,717 & $-0.27^{* *}$ \\
\hline No Participation in Groups & $-0.08 * * *$ & 1.11 & 1,679 & 0.73 & 3,505 & $-0.35^{* * *}$ \\
\hline Feeding Infants & 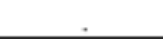 & . & . & 3.02 & 1,094 & . \\
\hline
\end{tabular}

Note: The significance level presented in the last column results from a two-group mean-comparison test with unequal variance taking into consideration the survey design. ${ }^{* * *} p<0.01,{ }^{* *} p<0.05,{ }^{*} p<0.1$ 
Our sample of women mostly includes household heads, spouses of household heads, and daughters of household heads. So, we examine the relationship between women's relative autonomy and their position in the household. The correlations presented in Table 6.2 show that women who are the household head tend to be more autonomously motivated in the domains of Household Activities, Employment and No Participation in Groups than other women. Women's autonomy in other domains does not seem to be correlated with their position in the household.

Table 6.3 presents the pairwise correlations between domain-specific relative autonomy indexes and individual and household characteristics, for the sample of women and men separately. This table shows that women's autonomy in most domains is positive correlated with age, while men's age does not seem to be related with autonomy in any particular domain. Please note, however, that all men in our sample are household heads. If we examine the correlation between relative autonomy and age of women who are household heads, we also find no statistically significant relationship. On the other hand, this relationship remains significant in the domains of Household Activities, Employment and No Employment, among women who are not household heads. So, it is possible that household heads autonomy does not depend on age.

We also note in Table 6.1 and Table 6.2 that the RAI scores on 'positive' domains are larger than those on 'negative' domains for all groups (women, men, household heads, spouses, and daughters). There may be data quality challenges in responses to negative domains, because the situation may not have been consciously sought, and we recommend that future surveys also undertake cognitive interviews to verify the extent to which the levels are comparable across negative and positive domains.

We find no evidence of a relationship between education level and relative autonomy in the sample of women; but in the sample of men we find that more educated men tend to have higher levels of autonomy in the domains of Household Activities, Employment and Participation and Non-Participation in Groups. ${ }^{11}$ On the other hand, women's relative autonomy seems to be positively associated with the education level of the household head. Women living in households where the head is more educated are more autonomously motivated in the domains of Household Activities, Employment, Participation in Groups and Feeding Infants. This is in line with literature on positive externalities of husband's education and its promotion of shared decision making. For example, Grabowski and Self (2013) find in India that husband's education as well as mother's decision making autonomy increases the likelihood of skilled medical attention for their child.

\footnotetext{
${ }^{11}$ As Pearson correlation only identifies linear relationships between variables, this evidence does not preclude the possibility of a non-linear relationship between women's education and relative autonomy.
} 
Table 6.2 Correlation and mean comparisons of women's RAI by their position in the household

\begin{tabular}{|c|c|c|c|c|c|c|c|c|c|}
\hline \multirow{4}{*}{ RAI in... } & \multicolumn{3}{|c|}{ Pearson Correlations } & \multicolumn{6}{|c|}{ Mean comparisons } \\
\hline & \multirow{2}{*}{$\begin{array}{c}\text { Household } \\
\text { head }\end{array}$} & \multirow{2}{*}{$\begin{array}{c}\text { Spouse of } \\
\text { head }\end{array}$} & \multirow{2}{*}{$\begin{array}{c}\text { Daughter of } \\
\text { head }\end{array}$} & \multicolumn{2}{|c|}{ Household head } & \multicolumn{2}{|c|}{ Spouse } & \multicolumn{2}{|c|}{ Daughter } \\
\hline & & & & Mean & Obs & Mean & Obs & Mean & Obs \\
\hline & (1) & $(2)$ & (3) & (4) & (5) & (6) & (7) & $(8)$ & (9) \\
\hline Houschold Activities & $0.11^{* \approx *}$ & $-0.05^{* *}$ & $-0.05^{* * *}$ & 2.89 & 4,068 & 2.08 & 3,123 & 1.86 & 988 \\
\hline Employment & $0.17^{* \approx *}$ & $-0.10^{* *}$ & -0.02 & 3.75 & 2,895 & 2.66 & 1,240 & 2.66 & 283 \\
\hline Making Houschold Purchases & -0.07 & -0.03 & 0.08 & 3.99 & 1,237 & 3.99 & 330 & 4.78 & 55 \\
\hline Not making Houschold Purchases & 0.04 & 0.00 & -0.01 & 0.42 & 2,872 & 0.26 & 2,565 & 0.24 & 868 \\
\hline Participation in Groups & 0.05 & 0.02 & -0.04 & 4.07 & 1,724 & 3.81 & 1,054 & 3.47 & 230 \\
\hline No Participation in Groups & $0.07^{*}$ & -0.03 & -0.03 & 1.10 & 2,314 & 0.67 & 1,896 & 0.58 & 694 \\
\hline Feeding infants & 0.00 & -0.01 & 0.03 & 3.06 & 110 & 3.01 & 876 & 3.27 & 80 \\
\hline
\end{tabular}

Note: ${ }^{* 4 *} \mathrm{p}<0.01,{ }^{* *} \mathrm{p}<0.05,{ }^{*} \mathrm{p}<0.1$ 
Table 6.3: Pearson correlations between RAI and individual and household characteristics

\begin{tabular}{|c|c|c|c|c|c|c|c|c|c|c|c|}
\hline \multirow{3}{*}{ RAI in domain... } & \multicolumn{6}{|c|}{ Individual's characteristics } & \multicolumn{5}{|c|}{ Household's characteristics } \\
\hline & Age & $\begin{array}{c}\text { Education } \\
\text { level }\end{array}$ & Married & Working & $\begin{array}{l}\text { Participates } \\
\text { in a group }\end{array}$ & Disability & $\begin{array}{c}\text { Education level } \\
\text { of household } \\
\text { head }^{(1)}\end{array}$ & $\begin{array}{c}\text { Household's } \\
\text { expenditure } \\
\text { quintile }\end{array}$ & $\begin{array}{l}\text { Household } \\
\text { is poor }\end{array}$ & $\begin{array}{l}\text { Household } \\
\text { head is } \\
\text { Muslim }\end{array}$ & Urban areas \\
\hline & (1) & (2) & (3) & (4) & (5) & (6) & (7) & (8) & (9) & (10) & (11) \\
\hline & \multicolumn{11}{|c|}{ Sample of Women } \\
\hline Houschold activities & $0.11^{* 8 *}$ & 0.04 & $-0.04^{*}$ & 0.04 & $0.13^{* * *}$ & $0.07^{* z}$ & $0.10^{* \approx *}$ & 0.00 & 0.00 & $-0.12^{* * *}$ & $0.06^{* z}$ \\
\hline Employment & $0.14^{* * *}$ & 0.05 & -0.08 & . & 0.04 & 0.01 & $0.10^{* * *}$ & 0.02 & -0.01 & $-0.09 *$ & $0.13^{* 8 * 8}$ \\
\hline No employment & $0.07^{* * *}$ & -0.05 & 0.02 & . & $0.07^{*}$ & 0.03 & -0.02 & -0.04 & 0.03 & 0.00 & 0.00 \\
\hline Make purchases & -0.08 & 0.09 & -0.13 & 0.03 & 0.08 & -0.07 & 0.10 & -0.07 & 0.03 & $-0.21^{* * *}$ & -0.01 \\
\hline Not making purchases & $0.04^{*}$ & -0.04 & 0.04 & 0.01 & 0.05 & -0.03 & $-0.06^{* *}$ & $0.06^{*}$ & -0.06 & $0.11^{* * *}$ & -0.02 \\
\hline Participation in groups & 0.04 & 0.00 & 0.00 & -0.01 & & 0.01 & $0.15^{* *}$ & 0.00 & 0.02 & -0.13 & -0.01 \\
\hline No participation in groups & $0.06^{*}$ & 0.04 & -0.01 & 0.04 & . & 0.03 & 0.06 & 0.01 & -0.01 & $-0.07^{*}$ & 0.03 \\
\hline \multirow[t]{2}{*}{ Infants nutrition } & 0.01 & 0.04 & $-0.09^{* *}$ & 0.09 & 0.10 & 0.05 & $0.10^{* *}$ & 0.07 & $-0.12^{*}$ & $-0.18^{* * *}$ & 0.01 \\
\hline & \multicolumn{11}{|c|}{ Sample of Men } \\
\hline Houschold activities & -0.03 & $0.16^{* * z}$ & $-0.08^{* * *}$ & $0.14^{* * *}$ & $0.07^{*}$ & 0.00 & . & $-0.06^{*}$ & $0.07^{*}$ & $-0.21^{* * *}$ & $0.06^{* *}$ \\
\hline Employment & 0.01 & $0.09^{* x *}$ & -0.01 & & 0.02 & -0.04 & & -0.03 & 0.02 & $-0.18^{* * *}$ & -0.04 \\
\hline No employment & -0.01 & -0.04 & -0.03 & . & -0.06 & 0.03 & . & -0.01 & 0.04 & 0.05 & 0.01 \\
\hline Make purchases & -0.04 & 0.05 & -0.04 & 0.04 & 0.04 & -0.05 & . & 0.07 & $-0.10^{* *}$ & $-0.16^{* * *}$ & 0.00 \\
\hline Not making purchases & 0.00 & -0.05 & 0.02 & 0.01 & 0.03 & 0.04 & . & $0.10^{*}$ & -0.08 & $0.10^{*}$ & -0.04 \\
\hline Participation in groups & 0.02 & $0.15^{* * *}$ & -0.04 & 0.01 & . & 0.00 & & -0.07 & 0.07 & -0.16 & -0.01 \\
\hline No participation in groups & 0.01 & $0.13^{* * *}$ & $-0.06 * * *$ & $0.12^{* s}$ & & 0.05 & & 0.00 & -0.02 & $-0.18^{* * *}$ & $0.09^{* *}$ \\
\hline
\end{tabular}

(1) Women who are the household head were excluded from the estimation sample.

Note: ${ }^{* * * *} \mathrm{p}<0.01,{ }^{* *} \mathrm{p}<0.05,{ }^{*} \mathrm{p}<0.1$ 
Both married women and men tend to have lower levels of autonomy in terms of household activities, probably because these result from a bargaining process between the spouses. Single individuals make decisions alone or might have lower responsibilities in terms of domestic chores; while married individuals have to share the decisions and make compromises. Married women also report lower relative autonomy in feeding infants. Working is associated with higher relative autonomy of men in household activities, but it has no relationship with women's relative autonomy in any domain. Maybe men who work outside the house can reduce their partaking in the household chores, while women cannot. Being part of a group is associated with higher autonomy of women in the domains of Household Activities and No Employment. While participation in groups is very broadly defined, covering multiple groups, and not specifying the extent of participation in the group nor its structure, neither the frequency of meetings, these findings support the suggestion that group membership is associated with greater autonomy.

Women living in poor households have lower levels of relative autonomy in feeding infants, but similar levels in other domains. Finally, women and men living in Muslim households have significantly lower relative autonomy in most domains.

We find that some demographic features do seem to discriminate between levels of autonomy whereas others - including income and education - require further interpretation. This analysis also highlights two features. First, the set of variables that are associated with relative autonomy is different for women and men. For instance, age is associated with relative autonomy of women, but not with men's. Second, the characteristics that discriminate between levels of autonomy vary across domains of decision-making. For example, participation in a group seems to be correlated with higher autonomy in household activities, but has no statistical relationship with autonomy in employment. Furthermore, all correlations discussed in this section are relatively weak, never beyond 0.25 (or -0.25 ). This strongly suggests that none of these categories alone is a sufficient proxy for autonomy across either women or men.

\subsection{Regression Analysis}

In order to analyze the relationship between autonomy and individual's characteristics taking into account possible interactions between these characteristics we conduct a multivariate regression analysis.

\subsubsection{Empirical Specification}

We estimate the following equation:

$$
\boldsymbol{R A I} \boldsymbol{I}_{i}=\boldsymbol{\beta}_{0}+\boldsymbol{\beta}_{1} \boldsymbol{X}_{i}+\boldsymbol{\varepsilon}_{i}
$$

where $\boldsymbol{R} \boldsymbol{A I} \boldsymbol{I}_{i}$ is the vector of individual i's relative autonomy indexes in the different domains, $\boldsymbol{X}_{i}$ is a vector of individual and household characteristics, and $\boldsymbol{\varepsilon}_{i}$ is an error term. The vector 
$\boldsymbol{X}_{i}$ includes all characteristics discussed in the correlation analysis, plus the number of household members and number of household members younger than 6 years old.

Equation (1) is estimated separately for women and men, using OLS and taking into account the survey design (using svy commands). All regressions include region dummies to control for location specific effects.

\subsubsection{Results}

Estimates of equation (1) for the RAI in domains of household activities, employment, participation in groups and feeding infants (only for women) are presented in Tables 7.1 (sample of women) and 7.2. (sample of men). ${ }^{12}$ As the expenditure data is only available for a subsample of households, for each RAI we present two sets of results: one without household poverty status, and another with such control. In the sample of women we present a third specification, which includes the education level of the household head and is estimated considering only the sample of women who live in male headed households.

The regression results, in general, corroborate the pattern of relationships identified by the correlation analysis.

As suggested by the results of the correlation analysis, women who are the household head tend to be more autonomously motivated than other women, ceteris paribus.

Even when controlling for other variables, older women tend to have higher relative autonomy in household activities and employment. On the other hand, when we take into consideration other characteristics, we find evidence of a positive relationship between men's age and their autonomy in participating in groups.

This analysis also does not support the hypothesis that women's education is associated with higher autonomy. In contrast, in the sample of men, we find evidence of a strong relationship between education and relative autonomy in all domains presented in the table. If we look only to the sub-sample of women who are not household heads, we find that the education of the household head has a positive impact on women's autonomy in Household Activities and in Participation in Groups.

As suggested by the correlation analysis, married men tend to have lower levels of autonomy in Household Activities. In the case of women, on the other hand, being married only has a negative effect on autonomy in feeding infants.

\footnotetext{
${ }^{12}$ The estimates of the regressions of RAI in other domains are available upon request.
} 
Table 7.1: Regressions of RAI in four domains, Equation (1) - Sample of Women

\begin{tabular}{|c|c|c|c|c|c|c|c|c|c|c|c|c|}
\hline \multirow{3}{*}{ Variables } & \multicolumn{12}{|c|}{ RAI in domains... } \\
\hline & \multicolumn{3}{|c|}{ Household activities } & \multicolumn{3}{|c|}{ Employment } & \multicolumn{3}{|c|}{ Participation in groups } & \multicolumn{3}{|c|}{ Feeding infants } \\
\hline & (1) & (2) & (3) & (4) & (5) & (6) & (7) & (8) & (9) & (10) & (11) & (12) \\
\hline Age & $\begin{array}{c}0.016^{* * *} \\
(0.005)\end{array}$ & $\begin{array}{c}0.018^{* * *} \\
(0.006)\end{array}$ & $\begin{array}{c}0.022^{* * 3} \\
(0.007)\end{array}$ & $\begin{array}{l}0.019^{* *} \\
(0.009)\end{array}$ & $\begin{array}{l}0.023^{* z} \\
(0.011)\end{array}$ & $\begin{array}{c}0.016 \\
(0.016)\end{array}$ & $\begin{array}{c}0.006 \\
(0.009)\end{array}$ & $\begin{array}{c}0.010 \\
(0.009)\end{array}$ & $\begin{array}{c}0.013 \\
(0.009)\end{array}$ & $\begin{array}{l}-0.014 \\
(0.024)\end{array}$ & $\begin{array}{l}-0.006 \\
(0.025)\end{array}$ & $\begin{array}{c}-0.012 \\
(0.024)\end{array}$ \\
\hline Household head & $\begin{array}{l}0.437^{*} \\
(0.261)\end{array}$ & $\begin{array}{c}0.388 \\
(0.278)\end{array}$ & & $\begin{array}{c}0.999 * \approx * \\
(0.333)\end{array}$ & $\begin{array}{c}1.025^{* * *} \\
(0.372)\end{array}$ & & $\begin{array}{l}0.539^{*} \\
(0.281)\end{array}$ & $\begin{array}{l}0.588^{* *} \\
(0.295)\end{array}$ & & $\begin{array}{c}0.348 \\
(0.696)\end{array}$ & $\begin{array}{c}0.253 \\
(0.726)\end{array}$ & \\
\hline Only completed primary education & $\begin{array}{c}0.036 \\
(0.131)\end{array}$ & $\begin{array}{c}0.012 \\
(0.137)\end{array}$ & $\begin{array}{c}0.017 \\
(0.147)\end{array}$ & $\begin{array}{l}-0.070 \\
(0.244)\end{array}$ & $\begin{array}{l}-0.092 \\
(0.304)\end{array}$ & $\begin{array}{c}-0.102 \\
(0.376)\end{array}$ & $\begin{array}{c}0.053 \\
(0.272)\end{array}$ & $\begin{array}{l}-0.015 \\
(0.300)\end{array}$ & $\begin{array}{l}-0.114 \\
(0.359)\end{array}$ & $\begin{array}{l}-0.305 \\
(0.308)\end{array}$ & $\begin{array}{l}-0.183 \\
(0.288)\end{array}$ & $\begin{array}{c}-0.457 \\
(0.303)\end{array}$ \\
\hline Completed secondary education & $\begin{array}{c}0.197 \\
(0.185)\end{array}$ & $\begin{array}{c}0.180 \\
(0.220)\end{array}$ & $\begin{array}{c}0.272 \\
(0.263)\end{array}$ & $\begin{array}{c}0.007 \\
(0.420)\end{array}$ & $\begin{array}{c}-0.048 \\
(0.503)\end{array}$ & $\begin{array}{c}0.090 \\
(0.602)\end{array}$ & $\begin{array}{c}-0.384 \\
(0.421)\end{array}$ & $\begin{array}{l}-0.339 \\
(0.444)\end{array}$ & $\begin{array}{c}-0.482 \\
(0.475)\end{array}$ & $\begin{array}{c}-0.477 \\
(0.471)\end{array}$ & $\begin{array}{c}-0.510 \\
(0.558)\end{array}$ & $\begin{array}{l}-0.729 \\
(0.597)\end{array}$ \\
\hline Married or in an union & $\begin{array}{l}-0.108 \\
(0.117)\end{array}$ & $\begin{array}{l}-0.131 \\
(0.129)\end{array}$ & $\begin{array}{l}-0.220 \\
(0.150)\end{array}$ & $\begin{array}{c}0.069 \\
(0.385)\end{array}$ & $\begin{array}{c}0.179 \\
(0.422)\end{array}$ & $\begin{array}{c}0.577 \\
(0.565)\end{array}$ & $\begin{array}{c}0.222 \\
(0.209)\end{array}$ & $\begin{array}{c}0.254 \\
(0.232)\end{array}$ & $\begin{array}{c}0.284 \\
(0.337)\end{array}$ & $\begin{array}{c}-0.856 \\
(0.561)\end{array}$ & $\begin{array}{l}-1.142^{*} \\
(0.667)\end{array}$ & $\begin{array}{c}-0.973 \\
(1.027)\end{array}$ \\
\hline Worked & $\begin{array}{l}-0.068 \\
(0.236)\end{array}$ & $\begin{array}{l}-0.088 \\
(0.240)\end{array}$ & $\begin{array}{l}-0.173 \\
(0.271)\end{array}$ & & & & $\begin{array}{l}-0.085 \\
(0.193)\end{array}$ & $\begin{array}{c}0.076 \\
(0.200)\end{array}$ & $\begin{array}{c}0.088 \\
(0.220)\end{array}$ & $\begin{array}{c}0.118 \\
(0.303)\end{array}$ & $\begin{array}{c}0.133 \\
(0.305)\end{array}$ & $\begin{array}{l}-0.140 \\
(0.319)\end{array}$ \\
\hline Participates in a group & $\begin{array}{c}0.562^{* * *} \\
(0.211)\end{array}$ & $\begin{array}{c}0.620^{* \approx *} \\
(0.220)\end{array}$ & $\begin{array}{l}0.510^{* *} \\
(0.211)\end{array}$ & $\begin{array}{c}0.038 \\
(0.222)\end{array}$ & $\begin{array}{c}-0.008 \\
(0.281)\end{array}$ & $\begin{array}{c}0.014 \\
(0.352)\end{array}$ & & & & $\begin{array}{c}0.463 \\
(0.381)\end{array}$ & $\begin{array}{c}0.199 \\
(0.375)\end{array}$ & $\begin{array}{c}0.233 \\
(0.387)\end{array}$ \\
\hline Has a disability & $\begin{array}{c}0.123 \\
(0.207)\end{array}$ & $\begin{array}{c}0.034 \\
(0.217)\end{array}$ & $\begin{array}{c}0.160 \\
(0.245)\end{array}$ & $\begin{array}{l}-0.209 \\
(0.343)\end{array}$ & $\begin{array}{l}-0.359 \\
(0.394)\end{array}$ & $\begin{array}{l}-0.294 \\
(0.452)\end{array}$ & $\begin{array}{c}-0.102 \\
(0.200)\end{array}$ & $\begin{array}{c}-0.142 \\
(0.204)\end{array}$ & $\begin{array}{c}0.054 \\
(0.237)\end{array}$ & $\begin{array}{c}0.292 \\
(0.289)\end{array}$ & $\begin{array}{c}0.119 \\
(0.312)\end{array}$ & $\begin{array}{c}0.220 \\
(0.359)\end{array}$ \\
\hline No. of child under 6 in the household & $\begin{array}{l}0.134^{*} \\
(0.070)\end{array}$ & $\begin{array}{l}0.131^{*} \\
(0.072)\end{array}$ & $\begin{array}{l}0.136^{*} \\
(0.077)\end{array}$ & $\begin{array}{c}0.043 \\
(0.110)\end{array}$ & $\begin{array}{c}0.068 \\
(0.127)\end{array}$ & $\begin{array}{c}0.046 \\
(0.150)\end{array}$ & $\begin{array}{c}0.175 \\
(0.113)\end{array}$ & $\begin{array}{l}0.199^{*} \\
(0.115)\end{array}$ & $\begin{array}{l}0.257^{* 8} \\
(0.108)\end{array}$ & $\begin{array}{l}-0.105 \\
(0.129)\end{array}$ & $\begin{array}{c}0.030 \\
(0.129)\end{array}$ & $\begin{array}{l}-0.000 \\
(0.132)\end{array}$ \\
\hline No. of household members & $\begin{array}{c}-0.053^{* * *} \\
(0.018)\end{array}$ & $\begin{array}{l}-0.052^{* * *} \\
(0.021)\end{array}$ & $\begin{array}{c}-0.062^{* * *} \\
(0.026)\end{array}$ & $\begin{array}{c}0.020 \\
(0.045)\end{array}$ & $\begin{array}{c}0.020 \\
(0.048)\end{array}$ & $\begin{array}{c}0.032 \\
(0.062)\end{array}$ & $\begin{array}{c}-0.032 \\
(0.026)\end{array}$ & $\begin{array}{l}-0.037 \\
(0.030)\end{array}$ & $\begin{array}{c}-0.041 \\
(0.030)\end{array}$ & $\begin{array}{c}0.045 \\
(0.068)\end{array}$ & $\begin{array}{c}0.036 \\
(0.067)\end{array}$ & $\begin{array}{l}0.058 \\
(0.065)\end{array}$ \\
\hline Household head is Muslim & $\begin{array}{l}-0.572^{* *} \\
(0.237)\end{array}$ & $\begin{array}{l}-0.474^{* *} \\
(0.211)\end{array}$ & $\begin{array}{l}-0.552^{* *} \\
(0.234)\end{array}$ & $\begin{array}{l}-0.562^{* *} \\
(0.233)\end{array}$ & $\begin{array}{c}-0.734 * * * \\
(0.283)\end{array}$ & $\begin{array}{l}-0.767^{* *} \\
(0.379)\end{array}$ & $\begin{array}{c}-1.129 * * * \\
(0.432)\end{array}$ & $\begin{array}{l}-1.237^{* *} \\
(0.515)\end{array}$ & $\begin{array}{l}-1.139 * * \\
(0.551)\end{array}$ & $\begin{array}{l}-0.954^{* *} \\
(0.484)\end{array}$ & $\begin{array}{l}-1.320^{* *} \\
(0.553)\end{array}$ & $\begin{array}{c}-1.758^{* * *} \\
(0.541)\end{array}$ \\
\hline Urban Areas & $\begin{array}{c}0.399^{* * *} \\
(0.148)\end{array}$ & $\begin{array}{l}0.343^{* s} \\
(0.163)\end{array}$ & $\begin{array}{l}0.302^{*} \\
(0.159)\end{array}$ & $\begin{array}{l}0.890^{* * *} \\
(0.274)\end{array}$ & $\begin{array}{c}0.942^{* s *} \\
(0.293)\end{array}$ & $\begin{array}{l}1.285^{* * *} \\
(0.300)\end{array}$ & $\begin{array}{c}-0.027 \\
(0.301)\end{array}$ & $\begin{array}{l}-0.170 \\
(0.328)\end{array}$ & $\begin{array}{l}-0.422 \\
(0.369)\end{array}$ & $\begin{array}{l}0.115 \\
(0.295)\end{array}$ & $\begin{array}{c}0.018 \\
(0.298)\end{array}$ & $\begin{array}{c}0.090 \\
(0.309)\end{array}$ \\
\hline Household is poor & & $\begin{array}{l}-0.068 \\
(0.159)\end{array}$ & $\begin{array}{l}-0.070 \\
(0.172)\end{array}$ & & $\begin{array}{l}-0.162 \\
(0.250)\end{array}$ & $\begin{array}{l}-0.108 \\
(0.238)\end{array}$ & & $\begin{array}{c}0.020 \\
(0.199)\end{array}$ & $\begin{array}{l}-0.038 \\
(0.223)\end{array}$ & & $\begin{array}{c}-1.010^{* * *} \\
(0.368)\end{array}$ & $\begin{array}{l}-0.929 * * \\
(0.381)\end{array}$ \\
\hline $\begin{array}{l}\text { Household head has only completed } \\
\text { primary education }\end{array}$ & & & $\begin{array}{l}0.332^{*} \\
(0.171)\end{array}$ & & & $\begin{array}{c}0.027 \\
(0.240)\end{array}$ & & & $\begin{array}{c}0.178 \\
(0.252)\end{array}$ & & & $\begin{array}{l}-0.008 \\
(0.317)\end{array}$ \\
\hline $\begin{array}{l}\text { Household has completed secondary } \\
\text { education }\end{array}$ & & & $\begin{array}{c}0.104 \\
(0.218)\end{array}$ & & & $\begin{array}{c}0.304 \\
(0.443)\end{array}$ & & & $\begin{array}{c}1.017^{* * 8} \\
(0.365)\end{array}$ & & & $\begin{array}{c}0.079 \\
(0.479)\end{array}$ \\
\hline constant & $\begin{array}{l}1.017^{* *} \\
(0.490)\end{array}$ & $\begin{array}{l}0.898^{*} \\
(0.481)\end{array}$ & $\begin{array}{l}1.025^{* *} \\
(0.456)\end{array}$ & $\begin{array}{c}2.781^{* * *} \\
(0.652)\end{array}$ & $\begin{array}{c}2.770^{* * *} \\
(0.783)\end{array}$ & $\begin{array}{c}2.541^{* * *} \\
(0.900)\end{array}$ & $\begin{array}{c}2.966^{* * *} \\
(0.819)\end{array}$ & $\begin{array}{c}2.877^{* * *} \\
(0.937)\end{array}$ & $\begin{array}{c}2.739 * \approx * \\
(0.946)\end{array}$ & $\begin{array}{c}3.053^{* * *} \\
(1.049)\end{array}$ & $\begin{array}{c}3.861^{* * *} \\
(1.069)\end{array}$ & $\begin{array}{c}4.447^{* * *} \\
(1.307)\end{array}$ \\
\hline Region Dummies & Yes & Yes & Yes & Yes & Yes & Yes & Yes & Yes & Yes & Yes & Yes & Yes \\
\hline F-statistic & $6.572^{* \approx *}$ & $5.786^{* 2 *}$ & $9.853^{* * z}$ & $20.406^{* \approx *}$ & $11.637^{* \approx *}$ & $11.726^{* \approx *}$ & $20.036^{* \approx *}$ & $31.181^{* 2 *}$ & $43.910^{* \approx *}$ & $4.381 \%=8$ & $5.632^{* \approx *}$ & $3.903^{* * z}$ \\
\hline No. observations & 4,960 & 4,040 & 3,184 & 2,021 & 1,673 & 1,236 & 1,590 & 1,319 & 1,040 & 1,022 & 863 & 759 \\
\hline
\end{tabular}


Table 7.2: Regressions of RAI in three domains, Equation (1) - Sample of Men

\begin{tabular}{|c|c|c|c|c|c|c|}
\hline \multirow{3}{*}{ Variables } & \multicolumn{6}{|c|}{ RAI in domains... } \\
\hline & \multicolumn{2}{|c|}{ Household activities } & \multicolumn{2}{|c|}{ Employment } & \multicolumn{2}{|c|}{ Participation in groups } \\
\hline & (1) & (2) & (3) & (4) & (5) & (6) \\
\hline \multirow[t]{2}{*}{ Age } & 0.008 & 0.005 & 0.007 & 0.010 & $0.017^{* s}$ & $0.020^{* z}$ \\
\hline & $(0.007)$ & $(0.008)$ & $(0.008)$ & $(0.009)$ & $(0.007)$ & $(0.008)$ \\
\hline \multirow[t]{2}{*}{ Only completed primary education } & $0.369^{* *}$ & $0.430^{* *}$ & $0.564^{*}$ & $0.653^{*}$ & $0.574^{* *}$ & $0.575^{*}$ \\
\hline & $(0.188)$ & $(0.200)$ & $(0.329)$ & $(0.345)$ & $(0.270)$ & $(0.306)$ \\
\hline \multirow[t]{2}{*}{ Completed secondary education } & 0.332 & 0.313 & 0.082 & 0.167 & $0.698^{* *}$ & $0.770^{* *}$ \\
\hline & $(0.217)$ & $(0.231)$ & $(0.307)$ & $(0.331)$ & $(0.296)$ & $(0.333)$ \\
\hline \multirow[t]{2}{*}{ Married or in an union } & $-0.916^{* * *}$ & $-0.895^{* 4}$ & -0.232 & -0.095 & -0.443 & -0.207 \\
\hline & $(0.348)$ & $(0.392)$ & $(0.432)$ & $(0.470)$ & $(0.493)$ & $(0.623)$ \\
\hline \multirow[t]{2}{*}{ Worked } & $0.620^{* *}$ & $0.646^{* z}$ & & & $0.441^{*}$ & $0.438^{*}$ \\
\hline & $(0.253)$ & $(0.257)$ & & & $(0.249)$ & $(0.264)$ \\
\hline \multirow[t]{2}{*}{ Participates in a group } & 0.102 & 0.207 & -0.034 & 0.057 & & \\
\hline & $(0.162)$ & $(0.174)$ & $(0.159)$ & $(0.174)$ & & \\
\hline \multirow[t]{2}{*}{ Has a disability } & -0.170 & -0.083 & $-0.363^{*}$ & $-0.503^{* *}$ & -0.120 & -0.249 \\
\hline & $(0.192)$ & $(0.216)$ & $(0.207)$ & $(0.214)$ & $(0.253)$ & $(0.278)$ \\
\hline \multirow{2}{*}{ No. of child under 6 in the household } & $0.156^{*}$ & 0.126 & -0.061 & -0.059 & 0.140 & 0.118 \\
\hline & $(0.081)$ & $(0.080)$ & $(0.115)$ & $(0.100)$ & $(0.105)$ & $(0.110)$ \\
\hline \multirow[t]{2}{*}{ No. of household members } & -0.044 & -0.041 & 0.026 & 0.033 & $-0.059^{*}$ & $-0.061^{* *}$ \\
\hline & $(0.033)$ & $(0.034)$ & $(0.037)$ & $(0.040)$ & $(0.032)$ & $(0.031)$ \\
\hline \multirow[t]{2}{*}{ Household head is Muslim } & -0.315 & -0.339 & -0.519 & -0.548 & -0.552 & $-0.677^{*}$ \\
\hline & $(0.250)$ & $(0.293)$ & $(0.372)$ & $(0.435)$ & $(0.458)$ & $(0.403)$ \\
\hline \multirow[t]{2}{*}{ Urban Areas } & 0.074 & 0.106 & -0.176 & -0.302 & -0.175 & -0.149 \\
\hline & $(0.200)$ & $(0.214)$ & $(0.217)$ & $(0.237)$ & $(0.262)$ & $(0.267)$ \\
\hline \multirow[t]{2}{*}{ Houschold is poor } & & 0.124 & & -0.256 & & 0.267 \\
\hline & & $(0.236)$ & & $(0.215)$ & & $(0.259)$ \\
\hline \multirow[t]{2}{*}{ constant } & $2.600^{* 8 *}$ & $2.545^{* \approx *}$ & $3.540^{8 * 8}$ & $3.070^{\mathrm{*s*}}$ & $3.259^{* \approx *}$ & $2.872^{* x}$ \\
\hline & $(0.703)$ & $(0.762)$ & $(0.825)$ & $(0.884)$ & $(1.037)$ & $(1.140)$ \\
\hline Region dummies & Yes & Yes & Yes & Yes & Yes & Yes \\
\hline F-statistics & $15.903^{* * *}$ & $14.898^{\approx * *}$ & $4.562^{* \approx *}$ & $4.936^{\approx * \approx}$ & $7.736^{* \approx *}$ & $7.638^{* 2 *}$ \\
\hline No. observations & 2,857 & 2,266 & 2,183 & 1,701 & 1,311 & 1,076 \\
\hline
\end{tabular}


Women's relative autonomy seems to be independent from their employment status. In the case of men, those who work tend to have higher autonomy in household activities. Participation in a group, on the other hand, has a positive relationship with women's autonomy in household activities, but no relation with men's relative autonomy.

The regression results confirm that women living in Muslim households have lower autonomy in the domains of Household Activities, Employment, Participation in Groups and Feeding Infants. But in the case of men in Muslim households, the negative relationship is only significant in the domain of Participation in Groups.

Women living in urban areas have higher levels of autonomy in Household Activities and Employment. Women living in poor households have lower autonomy in feeding infants. ${ }^{13}$

Although the correlation analysis did not identify a significant association between disability and autonomy in any domain, the results presented in Table 7.2 show evidence of a negative relationship between disability and men's autonomy in the domain of Employment.

We find that the demographic composition of the household is related to women's relative autonomy. Ceteris paribus, in households with more children under six years old, women tend to be more autonomous in household activities and participation in groups; while in households with more people, women tend to be less autonomously motivated in Household Activities and men in Participation in Groups.

Although the coefficients are not presented in Tables 7.1 and 7.2, some of the location dummies are highly significant, especially in the regressions of women's relative autonomy in Household Activities and Employment. This suggests that there are local factors that have an important effect on women's autonomy.

This analysis highlights that the use of characteristics like education and income as proxies for autonomy is more problematic than what is usually assumed. In Chad, we find no relationship between women's education and relative autonomy. Women's autonomy in core activities like household chores and employment is more correlated with their age and whether they live in a city than with their education level or the poverty status (or expenditure level) of their household. This is corroborated by other studies in Africa, for example in Nigeria where women's age was found to confer influence over decision making (Gammage 1997). Mabsout (2011) in Ethiopia equally finds increased decision making among older women. Men's autonomy, on the other hand, is indeed associated with their level of education. This is the only variable that is statistically significant in the regressions of men's autonomy in the three domains presented in the table. However, men's autonomy in most domains has no relation with the level of expenditure of their household.

\footnotetext{
${ }^{13}$ We have also estimated all the regressions including the covariate household expenditure quintile instead of household poverty status. The coefficient of household expenditure quintile is significant in the same regressions that household poverty status is, but with the opposite sign.
} 
Interestingly, some of these results contrast with the findings reported by Vaz et al. (2014) in Bangladesh. Using a representative sample of Bangladesh rural population, these authors find no relationship between women's relative autonomy in a set of domains and their age or their position in the household. On the other hand, they find a robust positive relationship between men's relative autonomy and the household level of expenditure.

Lastly, our results indicate that motivational autonomy is stratified by religion, as women in Muslim households have a significantly lower score on their RAIs, especially in active domains.

\section{Conclusion}

In this contribution, we provide a detailed examination of a measure of motivational autonomy, the Relative Autonomy Index, using a nationally representative dataset of Chad. A distinctive feature of the survey is that it surveys men and women in the same household. The paper starts by investigating the conceptual validity of a measure of empowerment, which here is called autonomy, and assesses the internal consistency of its scale in this dataset. It then examines the correlations between domain-specific measures of autonomy and indicators of psychological and subjective wellbeing. Finally, the paper investigates the correlates of women's and men's domain-specific autonomy.

In terms of conceptual validation, the analysis of the dimensional structure of the data suggests that in Chad, two (rather than the usual three or four) dimensions distinguish the larger categories of motivation: controlled and autonomous. We confirm that the autonomy of Chad people can be assessed with reference to these two broad categories of motivation. The analysis of the correlation among motivation subscales shows an ordered pattern of correlation between the three types of motivation external, introjected and autonomous. In terms of reliability, Cronbach's Alpha indicates that the subscales in most domains are acceptable or good.

We find that relative autonomy is weakly correlated psychological well-being, but has no clear relationship with subjective wellbeing. In fact, we find that relative autonomy in some domains is even negatively correlated with indicators of overall life satisfaction and happiness. This suggests that the autonomy indicators yield new information that is not proxied by indicators of well-being. Investigating the relationship between relative autonomy and demographic characteristics, we find that women on average are significantly less autonomously motivated across all eight domains than men. We also conclude that neither education nor income are reasonable proxies for women's motivational autonomy. 


\section{References}

Abdi H. and Valentin D. (2007). "Multiple correspondence analysis," In: Salkind NJ, ed. Encyclopedia of Measurement and Statistics. Thousand Oaks, CA: Sage Publications; pp. 651-657.

Abell, N., Springer, D. W., \& Kamata, A. (2009). Developing and validating rapid assessment instruments. New York: Oxford University Press, Inc.

Alkire, S. (2005). "Subjective quantitative studies of human agency," Social Indicators Research, 74(1), pp. 217-260.

Alkire, S. (2008). "Concepts and Measures of Agency" in K. Basu and R. Kanbur, eds. Arguments for a Better World: Essays in Honor of Amartya Sen. Volume I: Ethics, Welfare and Measurement. Oxford: Oxford University Press. 2008. 455-474.

Alkire, S, Meinzen-Dick, R., Peterman, A., Quisumbing, A., Seymour, G. \& Vaz, A. (2013). "The Women's Empowerment in Agriculture Index," World Development, Vol. 52, pp. 71-91.

Alkire, S., Quisumbing, A., Sraboni, E. \& Vaz, A. (2013). "Measuring autonomy: Evidence from Bangladesh," Oxford Poverty and Human Development Initiative (OPHI) Research in Progress 38 .

Allen, E. \& Seaman, C. (2007). "Likert Scales and Data Analyses," Quality Progress, 40, 6465.

Alsop, R., Bertelsen, M. F., \& Holland, J. (2006). Empowerment in practice: From analysis to implementation. World Bank Publications.

Amzat, J. (2015). The question of autonomy in maternal health in Africa: A rights-based consideration. Journal of bioethical inquiry, 1-11.

Agarwala, R., \& Lynch, S. M. (2006). Refining the measurement of women's autonomy: An international application of a multi-dimensional construct. Social Forces, 84(4), 20772098 .

Balk, D. (1994). Individual and community aspects of women's status and fertility in rural Bangladesh. Population Studies, 48(1), 21-45. Chicago

Brown, J. (2011). "Likert Items and Scales of Measurement?" Shiken: JALT Testing \& Evaluation SIG Newsletter, 15 (1), pp. 10-14.

Carifio, J. \& Perla, R. (2007). "Ten Common Misunderstandings, Misconceptions, Persistent Myths and Urban Legends about Likert Scales and Likert Response Formats and their Antidotes," Journal of Social Sciences, Vol. 3(3), pp. 106-116.

Cortina, J. M. (1993). "What is Coefficient Alpha? An Examination of Theory and Applications," Journal of Applied Psychology, Vol. 78(1), pp. 98-104.

Chirkov, V. I., Ryan, R., Kim, Y., \& Kaplan, U. (2003). "Differentiating autonomy from individualism and independence: a self-determination theory perspective on internalization of cultural orientations and well-being," Journal of Personality and Social Psychology, 84(1), 97-110.

Chirkov, V. I. (2009). "A cross-cultural analysis of autonomy in education: A selfdetermination theory perspective," Theory and Research in Education, Vol. 7, pp. 253262. 
Chirkov, V. I., Ryan, R. M., \& Sheldon, K. M. (2011). Human autonomy in cross-cultural contexts: Perspectives on the psychology of agency, freedom, and well-being, Dordrecht: Springer.

Deci, E. L., \& Ryan, R. M. (1985). Intrinsic motivation and self-determination in human behavior. New York: Plenum Publishing Co.

Deci, E. L., \& Ryan, R. M. (Eds.). (2002). Handbook of self-determination research. Rochester, NY: The University of Rochester Press.

Deci, E. L., \& Ryan, R. M. (2012). Motivation, personality, and development within embedded social contexts: An overview of self-determination theory. In R. M. Ryan (Ed.), Oxford handbook of human motivation (pp. 85-107). Oxford, UK: Oxford University Press.

Ellerman, D. (2005). Helping People Help Themselves: From the World Bank to an Alternative Philosophy of Development Assistance, University of Michigan Press, 2005.

Guio, A.-C., Gordon, D. \& Marlier, E. (2012), "Measuring material deprivation in the EU: Indicators for the whole population and child-specific indicators", Eurostat Methodologies and working paper, Publications office of the European Union, Luxembourg, available from: http://epp.eurostat.ec.europa.eu/cache/ITY_OFFPUB/KSRA-12-018/EN/KS-RA-12-018-EN.PDF.

Hemker, B. T., Sijtsma, K., \& Molenaar, I. W. (1995). "Selection of unidimensional scales from a multidimensional item bank in the polytomous Mokken IRT model," Applied Psychological Measurement, Vol. 19(4), pp. 337-352.

Hindin, M. J., \& Muntifering, C. J. (2011). Women's autonomy and timing of most recent sexual intercourse in Sub-Saharan Africa: a multi-country analysis. Journal of sex research, 48(6), 511-519.

Ibrahim, S., \& Alkire, S. (2007). Agency and Empowerment: A Proposal for Internationally Comparable Indicators, University of Cambridge, Cambridge, UK. Sabina Alkire, University of Oxford, Oxford, UK.

Kishor, S., \& Subaiya, L. (2008). Understanding Women's Empowerment: A Comparative Analysis of Demographic and Health Surveys (DHS) Data. DHS Comparative Reports 20. Calverton, MD, US: Macro International.

Levesque, C. S., Williams, G. C., Elliot, D., Pickering, M. A., Bodenhamer, B. \& Finley, P. J. (2007). "Validating the theoretical structure of the Treatment Self-Regulation Questionnaire (TSRQ) across three different health behaviors," Health Education Research, Vol. 22(5), pp. 691-702.

Levine, R., Lloyd, C., Greene, M., \& Grown, C. (2009). Girls Count: A Global Investment \& Action Agenda. Washington, DC: Center for Global Development.

Malhotra, A., Schuler, S., \& Boender, C. (2002). Measuring women's empowerment as a variable in international development. Gender and Development Group. World Bank.

Narayan, D. (2005). Conceptual framework and methodological challenges. In D. Narayan (Ed.), Measuring empowerment: Cross disciplinary perspectives. The World Bank.

Ryan, R. M., \& Connell, J. P. (1989). "Perceived locus of causality and internalization: Examining reasons for acting in two domains," Journal of Personality and Social Psychology, 57, 749-761. 
Ryan, R. M., \& Deci, E. L. (2000). "Self-determination theory and the facilitation of intrinsic motivation, social development, and well-being," American Psychologist, 55(1), 68-78.

Ryan, R. M., Deci, E. L., \& Grolnick, W. S. (1995). "Autonomy, relatedness, and the self: their relation to development and psychopathology". In D. Cicchetti \& D. J. Cohen (Eds.), Developmental psychopathology: vol. 1. Theory and methods (pp. 618-655). New York: Wiley.

Samman, E. (2007). "Psychological and Subjective Well-being: A Proposal for Internationally Comparable Indicators," Oxford Development Studies 35(4), pp. 459486.

Samman, E., \& Santos, M. E. (2009). Agency and Empowerment: A review of concepts, indicators and empirical evidence.

Sijtsma, K., Meijer, R. R., \& Van der Ark, L. A. (2011). Mokken scale analysis as time goes by: An update for scaling practitioners. Personality and Individual Differences, Vol. 50, 31-37.

Simon, D., Adams, A. M., \& Madhavan, S. (2002). Women's social power, child nutrition and poverty in Mali. Journal of biosocial science, 34(2), 193-214.

Singh, K., Bloom, S., \& Brodish, P. (2015). Gender equality as a means to improve maternal and child health in Africa. Health care for women international, 36(1), 57-69.

Sraboni, E., Quisumbing, A. R., and Ahmed, A. U. (2013). The Women's Empowerment in Agriculture Index: Results from the 2011-2012 Bangladesh Integrated Household Survey. Project report submitted to the U.S. Agency for International Development. International Food Policy Research Institute, Dhaka. Downloadable at: http://ebrary.ifpri.org/cdm/ref/collection/p15738coll2/id/127504

Sraboni, E., Malapit, H., Quisumbing, A. R., and Ahmed, A. U. (2013). "Women's Empowerment in Agriculture: What Role for Food Security in Bangladesh?" ICAS VI Sixth International Conference in Agricultural Statistics. Unpublished Conference Paper.

Sen, A. K. (1985). "Well-being, agency and freedom: the Dewey lectures 1984," The Journal of Philosophy, 82(4), 169-221.

Sen, A. K. (1999). Development as Freedom. New York: Knopf.

United Nations Development Program. (2010). Human development report 2010: The Real Wealth of Nations: Pathways to Human Development. Retrieved from http://hdr.undp.org/en/content/human-development-report-2010.

United Nations Development Program. (2014). Human development report 2014: Sustaining human progress: Reducing vulnerabilities and building resilience. Retrieved from http:/hdr.undp.org/en/content/human-development-report-2014.World Development Report 2012: Gender Equality and Development. Washington DC: The World Bank.

WHO (2014). "Trends in maternal mortality: 1990 to 2013. Estimates by WHO, UNICEF." (2014). WHO, UNICEF, UNFPA, The World Bank and the United Nations Population Division.

Zavaleta, D. (2015). "Chad Multidimensional Deprivation and Vulnerability Survey Report," Oxford Poverty and Human Development Initiative (OPHI) Working Paper. 